\title{
SISTEM INFORMASI GMIT SONAF AMASAT HOINBALA MANUTAPEN BERBASIS WEB
}

\author{
Jemsrado Sine ${ }^{1}$, Lita A Ndolu ${ }^{2}$, Yuni P. Nubatonis ${ }^{3}$
}

\begin{abstract}
Abstrak :
Pengusulan Program Penelitian dan ini merupakan pelengkap penjelasan secara teknis bagi peneliti dan pelaksana dalam pemanfaatan Teknologi Informasi agar system dapat dimanfaatkan seefektif mungkin pada GMIT Sonaf Amasat Hoinbala Manutapen untuk mendukung kegiatan operasional sehari-hari, baik dalam proses pencarian data jemaat, majelis, rayon, pendeta, pelayanan dan keuangan agar tidak membutuhkan waktu yang cukup lama untuk melakukan kegiatan-kegiatan tersebut. Selain itu, sistem yang sedang berjalan pada GMIT Sonaf Amasat Hoinbala Manutapen ini menggunakan media kertas yang kurang menunjang untuk jangka waktu yang panjang karena jumlah data yang banyak, maka data yang ditampung akan semakin besar, sehingga akan memperlambat kinerja sistem untuk menyajikan informasi secara cepat dan tepat. Metode yang di gunakan dalam penelitian ini adalah : metode observasi, studi pustaka dan perancangan sistem. Tujuan penelitian ini adalah : dengan menggunakan sistem dan perancangan aplikasi yang terkomputerisasi, maka semua data dapat tersimpan dengan rapi, keamanan terjamin, pengolahan data atau informasi dapat dilakukan secara cepat, tepat dan akurat
\end{abstract}

Kata Kunci : Sistem informasi, Gereja, jemaat.

\section{PENDAHULUAN}

Teknologi informasi saat ini mengalami perkembangan di berbagai bidang, salah satunya adalah media internet melalui teknologi informasi semua orang dapat menggunakan sistem informasi dengan mudah dan cepat. Salah satu sistem informasi yang saat ini berkembang adalah website. Dengan adanya website dapat membantu banyak orang untuk memperoleh informasi secara umum, dan memberi wawasan yang lebih luas lagi.

Website saat ini terus berkembang untuk memenuhi kebutuhan informasi di berbagai bidang kehidupan. Disamping penyebaran informasi menggunakan website lebih merata, dengan website informasi dapat mengalir secara efektif dan efisien. Keunggulan inilah yang menjadikan website banyak berperan serta dalam segala bidang dan aspek kehidupan yang ada, dan berkembang sesuai kebutuhan masyarakat, dari perusahaan, institusi, sampai tempat ibadah mulai bergeser melakukan sistem komputerisasi di berbagai bidang sehingga sistem komputerisasi di gereja dapat menghasilkan banyak manfaat bagi umat Kristen sampai organisasi-organisasi yang ada.

Saat ini GMIT Sonaf Amasat Hoinbala Manutapen memiliki berbagai macam informasi, baik itu informasi, data kebaktian ,data jemaat, data majelis, data pendeta, data rayon, data pelayanan, data penerimaan keuangan, data pengeluaran keuangan, data kegiatan, data ibadah minggu dan informasi-informasi lainnya, namun media yang digunakan dalam penyampaian informasi pada GMIT Sonaf Amasat Hoinbala Manutapen masih 
menggunakan surat edaran pada liturgi Gereja yang akan dibacakan setiap minggunya. Permasalahan lain yang ditemukan yaitu sebagian besar informasi yang ada di Gereja masih tersimpan dalam bentuk arsip fisik atau dokumen tercetak, sehingga apabila dibutuhkan, bagian sekretariat harus mencari kembali arsiparsip tersebut untuk mendapatkan data yang dibutuhkan, media informasi gereja seperti ini dapat menyulitkan bagian administrasi dalam bekerja. Untuk itu, maka diperlukan media yang dapat dijadikan sarana penyimpanan dan penyampaian informasi untuk memudahkan majelis dan jemaat gereja dalam mengelola dan mengakses informasi yang dibutuhkan.

Selain itu dapat dengan mudah melakukan penambahan, pencarian, dan pengecekan informasi-informasi seputar kegiatan gerejawi yang dilakukan dengan mudah dan cepat, serta dapat meningkatkan kualitas pelayanan di GMIT Sonaf Amasat Hoinbala Manutapen.

Berdasarkan masalah di atas maka penulis akan melakukan penelitian dengan mengambil judul "Sistem Informasi GMIT Sonaf Amasat Hoinbala Manutapen Berbasis Web". Dengan menggunakan sistem informasi tersebut, maka umat Kriten Protestan yang menjadi jemaat di gereja tersebut dapat mengakses informasi pelayanan gereja secara mudah dan cepat, serta dapat dilakukan kapanpun dan dimanapun mereka berada.

\section{TINJAUAN PUSTAKA}

Pengertian sistem.

Sistem merupakan kumpulan dari beberapa bagian yang memiliki keterkaitan dan saling bekerja sama serta membentuk suatu kesatuan untuk mencapai suatu tujuan dari sistem tersebut. Maksud dari suatu sistem adalah untuk mencapai suatu tujuan dan sasaran dalam ruang lingkup yang sempit (Sutabri, 2012). Dengan demikian didalam suatu sistem, komponenkomponen ini tidak dapat berdiri sendiri, tetapi saling berhubungan dan membentuk suatu kesatuan sehingga dapat tercapai suatu sistem yang mempunyai karakteristik.

\section{METODE PENELITIAN}

\section{a.Metode Obervasi}

Mengadakan penelitian secara langsung terhadap objek yang akan diteliti oleh penulis.

\section{b.Metode Studi Pustaka}

Mengambil artikel-artikel dari internet, mengambil referensi dari buku-buku yang berhubungan dengan materi.

\section{c. Model Perancangan Sistem}

Metode yang digunakan dalam pembuatan Sistem Informasi GMIT Sonaf Amasat Hoinbala Manutapen berbasis web adalah:

\section{Menentukan Diagram Konteks}

Berikut adalah gambaran sistem informasi adalah :

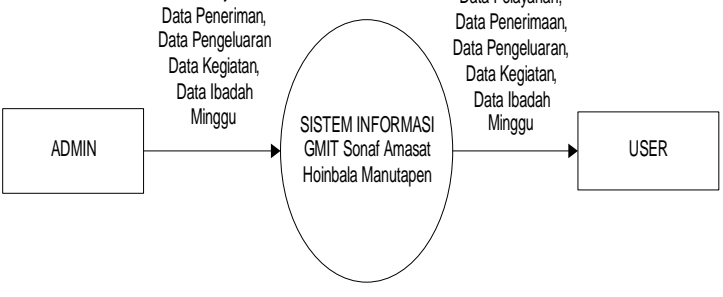

Gambar 1. Diagram Konteks

\section{Desain Alur Sistem dengan DFD ( Data Flow Diagram)}

Untuk memudahkan kita mengetahui gambaran proses kerja dari sistem yang akan dibangun, maka perlu dibuatkan bagan alur sistem. Berikut adalah gambaran alur sistem informasi akadmik di SMP Negeri 5 Kupang menggunakan system DFD (Data Flow Diagram). 


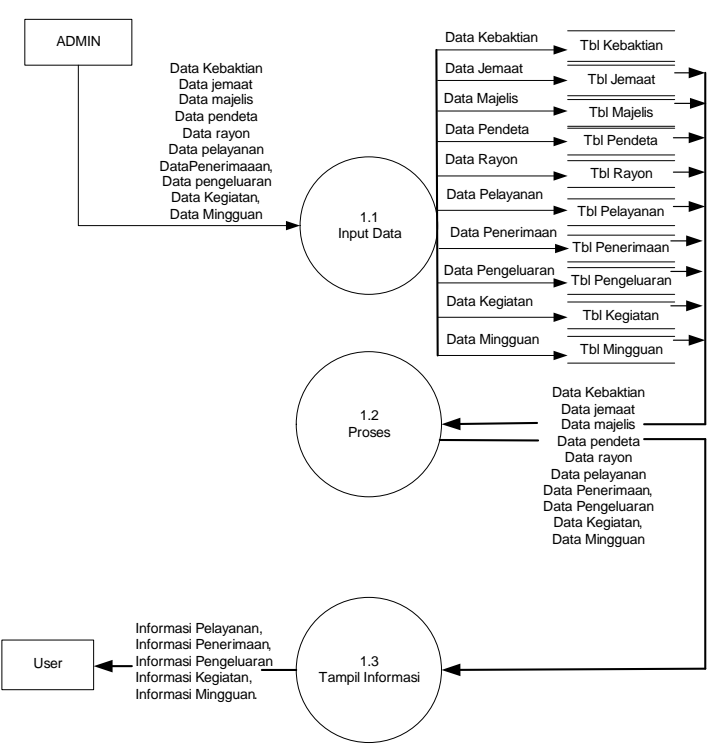

Gambar 2. DFD ( Data Flow Diagram).

\section{Desain ERD (Entity Relationship Diagram)}

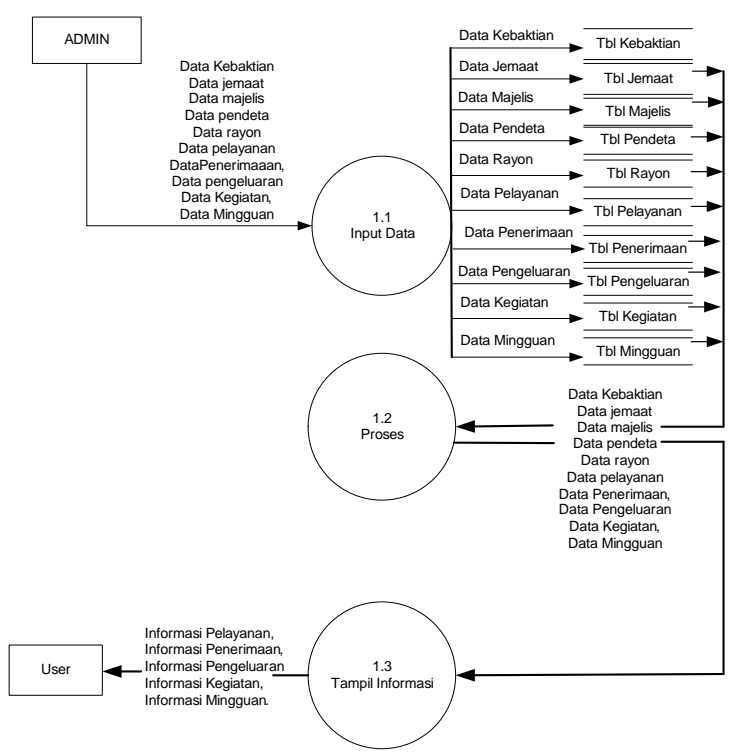

Gambar 3. Desain ERD

\section{HASIL DAN PEMBAHASAN}

\subsection{Hasil Pembuatan Sistem}

a.Halaman Login

- Tampilan halaman depan Sistem informasi GMIT Sonaf Amasat Hoinbala Manutapen.

Gambar 4. Tampilan halaman beranda

Pada gambar 4.23 tampilan beranda adalah tampilan dimana pengujung bisa melihat visi $\&$ misi serta membaca renungan.

- Tampilan halaman profil
Gambar 5. Tampilan halaman profil

Pada gambar 5 tampilan profil adalah tampilan dimana pengujung bisa melihat informasi tentang gereja. 
- Tampilan halaman informasi

Gambar 6. Tampilan halaman informasi

Pada gambar 6 tampilan halaman informasi adalah tampilan dimana pengujung bisa melihat informasi kegiatan, info mingguan, info keuangan, serta info pelayanan yang ada di dalam gereja.

- Tampilan halaman galeri
Pada gambar 7 tampilan halaman galeri adalah tampilan dimana pengujung bisa melihat foto kegiatan yang ada di dalam gereja.

\section{PENUTUP}

\subsection{Kesimpulan}

Dari hasil perancangan Sistem informasi GMIT Sonaf Amasat Hoinbala Manutapen berbasis web, dapat di ambil kesimpulan sebagai berikut :

1.Sistem Informasi ini menampilkan pembahasan tentang gereja, yang informasinya lebih detail mengenai informasi data pelayanan dan data keuangan. Sehingga dapat membantu pendataan jemaat yang ada pada gereja.

2.Sistem Informasi ini dapat dijadikan sebagai sarana informasi yang baik bagi jemaat Sonaf Amasat Hoinbala Manutapen dalam mengakses informasi lebih cepat dan benar.

\subsection{Saran}

Adapun saran yang diusulkan untuk membuat sistem ini menjadi lebih baik adalah :

Sistem informasi GMIT Sonaf Amasat Hoinbala tidak terlepas dari kekurangan. HTML, PHP dan MySql merupakan program yang digunakan Sistem Informasi GMIT Sonaf Amasat Hoinbala Manutapen berbasis web. Diharapkan untuk dapat dikembangkan khususnya dalam pencarian data jemaat berdasarkan rayon. Selanjutnya Sistem Informasi GMIT Sonaf Amasat Hoinbala Manutapen berbasis web dapat dikembangkan sebagai situs resmi yang telah bekerja sama dengan GMITSonaf Amasat Hoinbala Manutapen.

\section{DAFTAR PUSTAKA}

Jogiyanto, HM. 2002. Analisis dan Desain system Informasi. Yogyakarta: Andi.

Jogiyanto, HM. 2005. Analisis dan Desain Sistem Informasi : Pendekatan Terstruktur Teori dan Praktik Aplikasi Bisnis. Yogyakarta: Andi.

Gambar 7. Tampilan halaman galeri 


\section{Jurnal Ilmiah FLASH Volume 3 Nomor 2 Desember 2017}

Junidar. 2012. Perancangan Sistem Informasi Akademik Di Universitas U'Budiyah Indonesia menggunakan PHP dan MySQL. Banda Aceh : STMIK U'Budiyah Indonesia.

Kristanto, Andri. 2008. Perancangan Sistem Informasi dan Aplikasinya. Yogyakarta: Gava Media.

Purwanto, 2014."Sistem Informasi gmit koinonia kupang Berbasis web “. Teknik Telekomunikasi ITS Surabaya.

Dillak, R., \& toamnanu, n. (2017). SISTEM INFORMASI PENELITIAN RUTIN BERBASIS WEB DI UNIT PENELITIAN DAN PENGABDIAN MASYARAKAT RUTIN (UPPM) POLITEKNIK NEGERI KUPANG. Jurnal Ilmiah Flash, 3(1), 17-27. doi:10.5281/zenodo.1117129

manulangga, g., \& gultom, s. (2016). SISTEM INFORMASI PENATALAYANAN JEMAAT GEREJA HKBP KUPANG BERBASIS WEB. Jurnal Ilmiah Flash, 2(2), 87-91. Retrieved from http:// jurnal.pnk.ac.id/ index.php/flash/article/ view/29
Shannon, Weaver, 1992. "Ilmu Perpustakaan \& Informasi and A Mathematical

Theory of Communication" http:/ pespmc1.vub.ac.be/books/Shannon-Theory Comm.pdf

Turban, McLean, Wetherbe 1990. "Introduction to Information Tecnology" New York: John Wiley \& sons.

Sudarmadji, P., \& Bani, A. (2017). PEMBUATAN APLIKASI PENDATAAN PADA SMA NEGERI 1 AMFOANG UTARA KABUPATEN KUPANG. Jurnal Ilmiah Flash, 3(1), 36-41. doi:10.5281/ zenodo.1117133 